\title{
Socio-cultural and Economic Impacts of BRT Peshawar
}

\author{
Mushtaq Ahmad ${ }^{1}$, Salman Saeed ${ }^{2}$, Alina Babar ${ }^{3}$, Farman Ullah $^{4}$ \\ ${ }^{1}$ Graduate Student, National Institute of Urban Infrastructure Planning, University of Engineering and \\ Technology Peshawar, Khyber Pakhtunkhwa, Pakistan, qatshum@gmail.com \\ ${ }^{2}$ Assistant Professor, National Institute of Urban Infrastructure Planning, University of Engineering and \\ Technology Peshawar, Khyber Pakhtunkhwa, Pakistan, salmansaeed@uetpeshawar.edu.pk \\ ${ }^{3}$ Graduate Student, National Institute of Urban Infrastructure Planning, University of Engineering and \\ Technology Peshawar, Khyber Pakhtunkhwa, Pakistan, alinababar1992@gmail.com \\ ${ }^{4}$ ZU Peshawar - The Urban Mobility Company Peshawar, Khyber Pakhtunkhwa, Pakistan, \\ engr.farmanullah@hotmail.com
}

\begin{abstract}
Huge transportation projects can affect inhabitants i.e. People living nearby the construction or have businesses along the route. During the previous decade the Government of Khyber Pakhtunkhwa has been working to develop an institutional framework for urban renewal especially focusing the city of Peshawar because Peshawar is the biggest city of Khyber Pakhtunkhwa and had a major problem of transport and eventually the Government of Khyber Pakhtunkhwa came up with a solution in the form of BRT (Bus rapid transit system) and started working on it immediately at $20^{\text {th }}$ October, 2017. While starting work on the project the Socio-cultural and economic impacts were ignored while preparing the feasibility report for BRT Peshawar. Also, the impacts during the construction time were not taken into consideration.

In this study we wanted to identify the socio-cultural and economic impacts of BRT Peshawar both During the construction time and after BRT got operational.

Impact identification was the most important task to initiate the study. So, after studying relevant literature the impacts were identified and structured questionnaire was prepared for further research. This questionnaire was tested by conducting a Pilot Survey and reliability analysis of the responses using SPSS which helped us in finalizing the questionnaire. Stratified sampling technique was used for distribution of questionnaires and a sample size of 385 was taken. The questionnaires were distributed according to the length of the corridor sections and we got our results from this survey. After this when the project started, we conducted another survey and got our results.

It was found that the commute time was increased because of congestions caused by the huge construction of BRT. While on the other hand those who had relatives on the opposite side of the fence, their meeting frequency decreased. Also, it was found that Pedestrian Road crossing and Vehicular U-turns became difficult. The Privacy of the inhabitants was not
\end{abstract}

disturbed due to the flyovers and the health was impacted badly. Overall BRT projects always have more positive impacts than negative impacts while during construction the impacts can be minimized if we identify them before starting the project.

Key words: BRT Peshawar, Impacts of BRT, Transportation of Peshawar, BRT in developing countries, Transport Management

\section{INTRODUCTION}

Construction and transportation projects can affect inhabitants i.e., people living nearby the construction or have businesses along the route, in many ways. The city of Peshawar is facing a major issue of transport on daily basis as the current transport system does not seem to fulfil the requirements of the passengers [1].

During the previous years the government of Khyber Pakhtunkhwa (GoKP) has been working to develop an institutional framework for urban renewal especially focusing the city of Peshawar. The major focus of the GoKP was to develop such an institutional framework which is fit for the 21st Century. Many public transport systems policies and investments have been done in Peshawar to tackle the problems of Peshawar[4]. There was no local transport on the major spine route as the local bus and wagon transport was diverted to another route i.e., the Saddar bazar, and one had to travel about 50 percent more to reach the major zones in the city while many places in the area are left without any local means of transport. This deficiency was fulfilled by taxi and fixed route taxi (ride sharing) (4- passengers sit and distribute a fare of PKR 280). This fare is higher and difficult for people to afford and significantly limits their mobility. Similarly, many problems have been reported by the users such as traffic congestion, long waiting time at stops, non-punctuality of Public transport, drawing at speeds below the designed speed, private vehicle intervention and increase in travel time. Congestion, carbon emission and road collisions are also important in terms of time, pollution and economic loss. Cities throughout the world are concerned to upgrade their 
transit services to divert people to public transport to tackle the mentioned problems [4].

To overcome the problem of mobility in the largest city of KP the government announced a multi-billion project in the name of Bus Rapid Transit System and broke the ground for multi billion project BRT on 20th October 2017 [3]. Below are the features of BRT Peshawar;

- 26 Kilometer Total Length of the Main Corridor

- $15 \mathrm{KM}$ on Ground

- 8 KM Flyover

- 3 KM Underpass

- 31 Stations

- Avg. distance between station $850 \mathrm{~m}$

- 3 Bus Depots (Chamkani, Hayatabad, and Dabgari)

- 3 Park and Ride Facility (Locations)

- Bicycle lane

- Complete revamp of Footpaths

- Secure

- Efficient

- Fast Journey

- Comfortable

- Reliable

- 8 Feeder routes (Currently not part of the project)

- Cost effective [1]

\subsection{Research Problem}

Pakistan due to its unique social and cultural dynamics may pose a different scenario compared to other countries that have adopted similar public transportation modes. So here the techniques may also be modified [5].

Other major conflicts at the city-level are the conflicts related to road space use between the different users. Except Ahmedabad all the BRT systems have been criticized for taking the prime road space by the local popular media [6]. This clearly shows that the urban opinion-making is carried by the vocal elite classes or politicians who are also the owners of private vehicles and who resist more equitable distributions of road space[7].

Apart from solving many problems BRT may give rise to many social and cultural problems as well which will need to be addressed during or right after the completion of the project.

\subsection{Objectives}

- To identify the social impacts of BRT Peshawar

- To identify the cultural impacts of BRT Peshawar

- To identify the economic impacts of BRT Peshawar

\section{MATERIALS AND METHODS}

\subsection{Impacts identification}

The research process comprised of the following steps. In the first step the impacts were identified while using the available literature. Different BRT systems were studied that were currently operational in Pakistan. Moreover, different published research papers were studied to get impacts identified.

As the sociocultural impacts are hard to count so we got frameworks about formulating the sociocultural impacts. The major thing these frameworks taught was that the questionnaire must be structured and close ended. Similarly, we found that the questions should not be open ended.

Katie small, Debora Edwards and Lynnaire Sheridan created a flexible framework for socio cultural impacts of small events. They have created two evaluations termed as Social impact evaluation (SIE) and Social impact Perception (SIP). According to them most impacts of events study the economic impacts mainly focusing on the economic gain of an event while very few researches are focused on socio cultural impacts. Further they developed a framework to measure the socio-cultural impacts. They developed a 5 stepped process that is mention below;

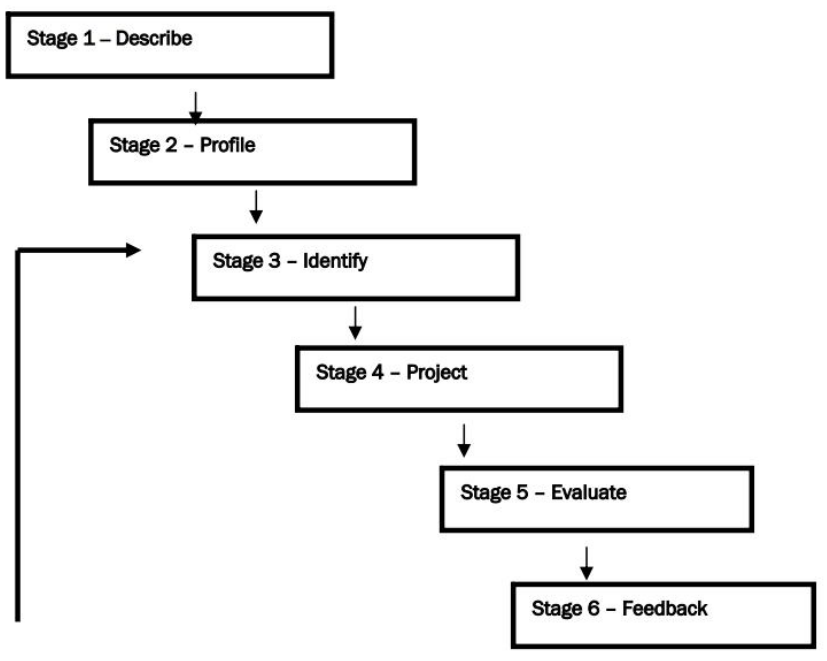

Figure 1: Figure showing the framework to measure the socio-cultural impacts [8]

\subsubsection{Describe}

In this step characteristics of events are described including type, activities offered, location and time, physical layout, geographical setting and details of festival and events funding and organizational structure [8].

\subsubsection{Profile}

In this stage destination profile for the host community is produced. This includes profile of the destination itself as well as characteristics of the subgroups of local residents most likely to be affected by the festival [8].

\subsubsection{Identify}

A range of potential socio-cultural impacts are identified which are most likely to occur. For this purpose, interviews with relevant people and desk research of existing impacts is of importance [8]. 


\subsubsection{Project}

In this stage the socio-cultural impacts that are most likely to occur are projected. The projections are made before the event and represents the pre-festival perception of people in contact [8].

\subsubsection{Evaluate}

After the event takes place, the socio-cultural impacts are studied. Which gives a data about the overall acceptability of the festival in the host community. Thorough data collection is required to make conclusions [8].

\subsubsection{Feedback}

The final findings are shared with the organizers to help them in future planning $[8]$.

After studying data from all the above-mentioned sources, we noted down all the impacts that other people have studied or have published. Then we removed those which were addressed by the officials in the studies i.e., feasibility report, Pre-feasibility report etc. So, I found a list of impacts that I wanted to identify in my study.

Below are some of the socio-cultural and economic impacts identified for the pre-evaluation of BRT. I believe many of the impacts are interrelated as well but let me first give the list.

\subsubsection{Socio-cultural Impacts}

Timing changes in business operation because of traffic congestion

Difficulties in road crossing

Opportunities for labor class

Issues raised because of sewerage

\subsubsection{Economic Impacts}

Fares Increase/ decrease

Rents Increase/ decrease

Property values increase/ decrease

Economic loss/gain in businesses

\subsubsection{Making a Structured Questionnaire}

The second step was the formation of questionnaire. So, a structured questionnaire was formed with the following sections;

- Information about the responder

- Social Impacts

- Cultural Impacts

- Environmental Impacts

\subsubsection{Use of Likert Scale}

Those questions in which we were able to use the Likert scale i.e., that is the 5-level answer, we preferred to use the likert scale in those questions.

\subsection{Pilot Survey}

After the above steps we made a questionnaire, now we wanted to know about any errors in our questionnaire. So, we filled the questionnaire from field professionals i.e. Urban Planners, Geographers and even architects (50 in total). This step helped us identify the problems in my questionnaire. Some academicians recommend 20 participants per question for pilot survey i.e., if you have 10 questions you will have to fill at least 200 questionnaires while others recommend about 35 to 60 participants.

A total of 50 questionnaires were filled and then SPSS was used carry out the reliability analysis while using the Cronbach's Alpha test. This helped in removing some of the questions to get a Cronbach's Alpha of 0.7 for all the questions asked.

\subsection{Sample Size}

The fourth step was to find the sample size and for this purpose the exact number impacted population was needed. To know the exact number a report shared by ADB (Project administration Manual); the number of population directly impacted by the BRT is $500,000(0.5$ million)[9]. With this number I calculated my sample size with 95 percent confidence level, 5 percent Error margin and response distribution 50 percent. The reason for selecting 50 percent response distribution was that it will give me the highest number.

With the above data the sample size was calculated as 384 .

\subsection{Sampling technique}

stratified sampling technique because the population was not consisted of a homogeneous group of people

\subsection{Survey Area}

As there were three major parts of the project i.e., the on-grade section, underground section and elevated section and I needed to get data from all of them so i split my questionnaires into 3 based on the length of each section. For example, the total length of the project is $26 \mathrm{~km}$, and I these $26 \mathrm{~km} 15 \mathrm{~km}$ is on grade, $8 \mathrm{~km}$ is flyover and the rest $3 \mathrm{~km}$ are underpass so;

$(3 \div 26) 385=44$ (Underground section)

$(8 \div 26) 385=118$ (Flyover section)

$(15 \div 26) 385=222$ (On-ground section)

After finding this, I filled my questionnaires at the areas as mentioned above. 
Mushtaq Ahmad et al., International Journal of Emerging Trends in Engineering Research, 9(6), June 2021, 759 - 764

\section{RESULTS AND DISCUSSION}

\subsection{Socio-cultural Impacts}

\subsubsection{Changes in timing}

BRT project claims to reduce travel time but due to the prolonged construction time it has affected the inhabitants the other way, we saw from the answers that mostly the commute time to and from work has been increased.

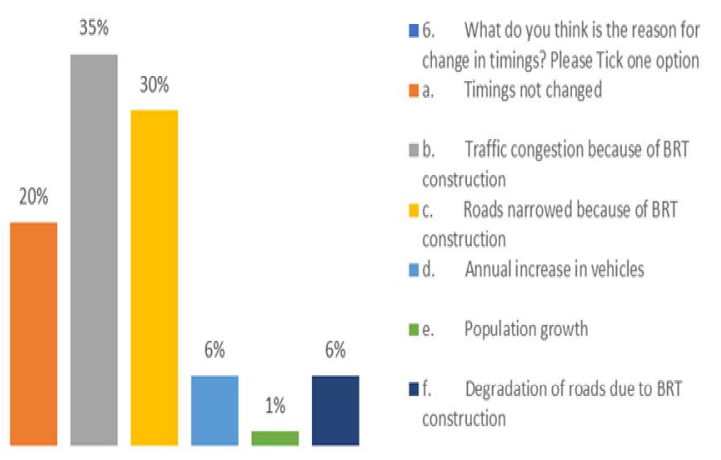

Figure 1: Graph showing responses regarding timing changes

After this we wanted to confirm the cause of difference in commute time so we added a question regarding that and the results we got are as below;

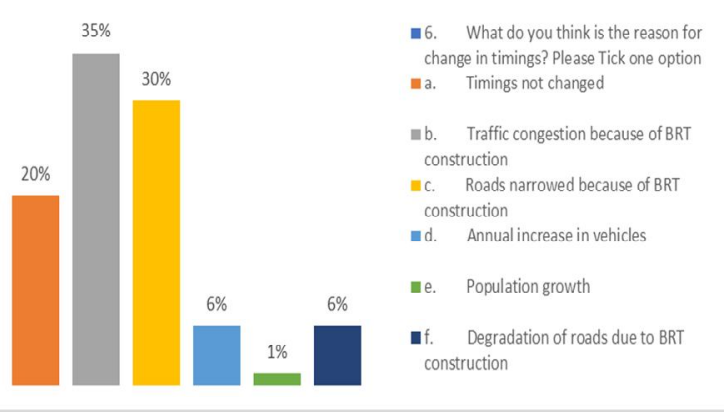

Figure 2: Graph showing the reason for change in timings

\subsubsection{Meeting Relatives}

This aspect was covered in two questions, the first one was to find whether someone has relatives or friends who are living on opposite side of the fenced road and the second one was to find the frequency of meetings before and after BRT construction was initiated.

It was found that those who were meeting their friends and family very frequently were affected more as compared to those whose meeting frequency was low before the construction of BRT.

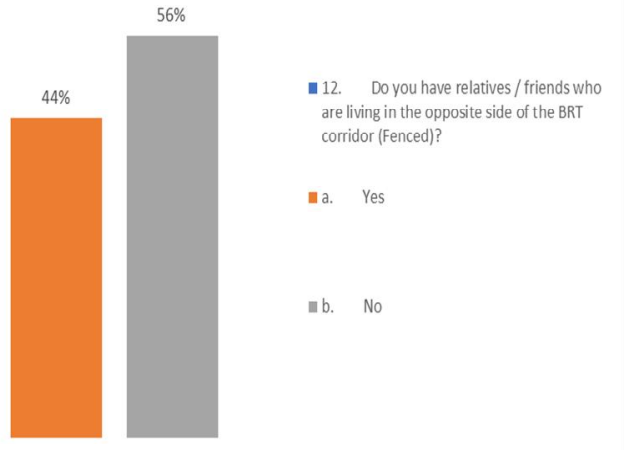

Figure 2: Graph showing the percentage of people who have friends and family living on the opposite side of the fence

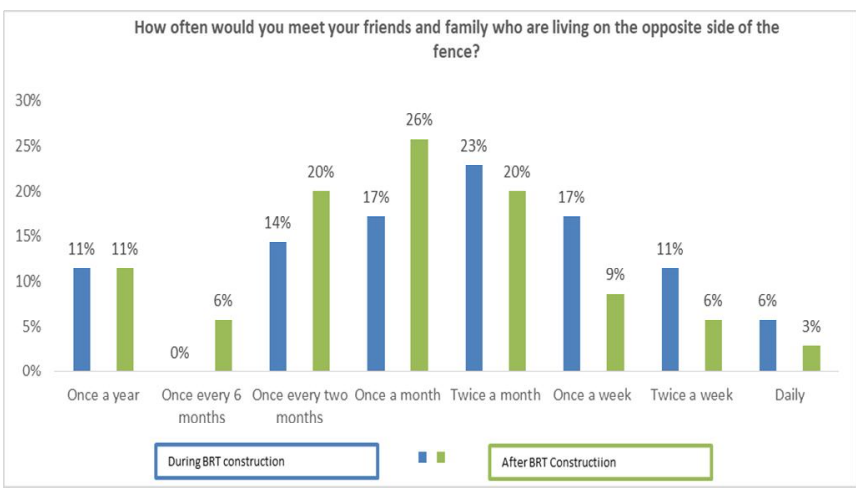

Figure 3: Figure showing the meeting frequency before and during the BRT construction activity

\subsubsection{Road Crossings}

This question was subdivided into two, the first one was road crossing and the second one was vehicular U-Turns. And the response was completely in the favor that road crossings have become difficult.

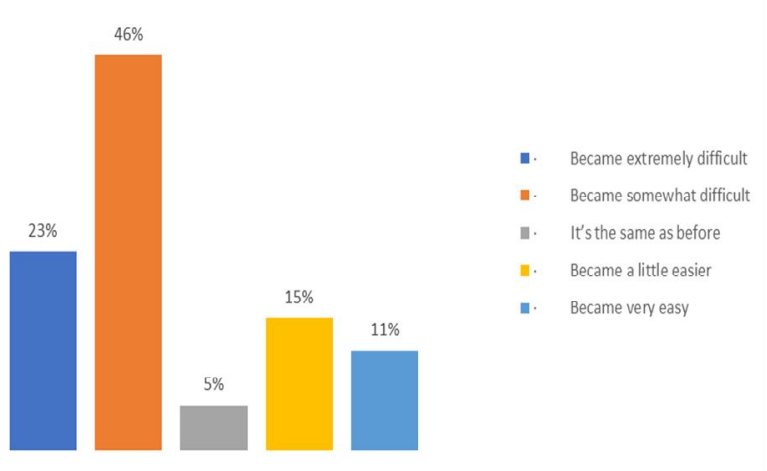

Figure 4: Figure showing the responses regarding Road crossing 


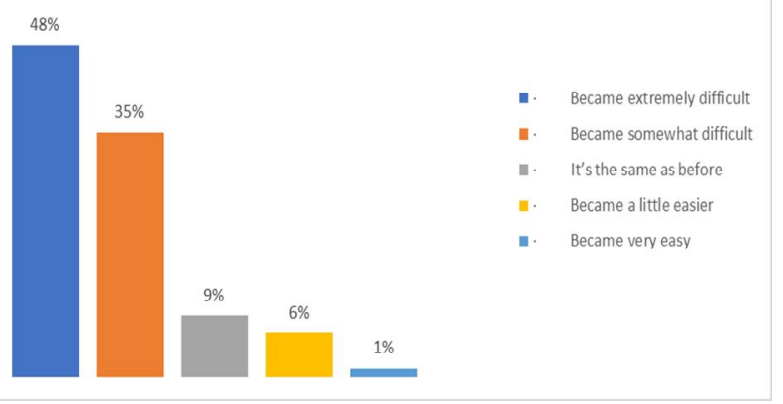

Figure 5: Figure showing the responses regarding vehicular U-Turns

In both of the above graphs we can see the both Road crossings and Vehicular U-Turns have become difficult as in both the cases $69 \%$ and $83 \%$ of the responses are in the favor that the crossing or taking turn has become difficult.

\subsection{Economic Impacts}

From different studies, it was found that business community is the one that is extremely impacted during the BRT construction. The total loss or gain is not known but we wanted to know how the business community is impacted during the BRT construction. Our study is not totally about economic impacts that's why we just added a section of responses from those who are operating businesses on the route. One other major thing that is impacted during huge construction activities is the Fares and Rents. The results are as followed.

\subsubsection{Fares Increase/ Decrease}

It is normally observed that areas where huge construction activities are taking place, the fares are also impacted. After the survey we found that the total fares have increased for all modes of transport. The results are as below;

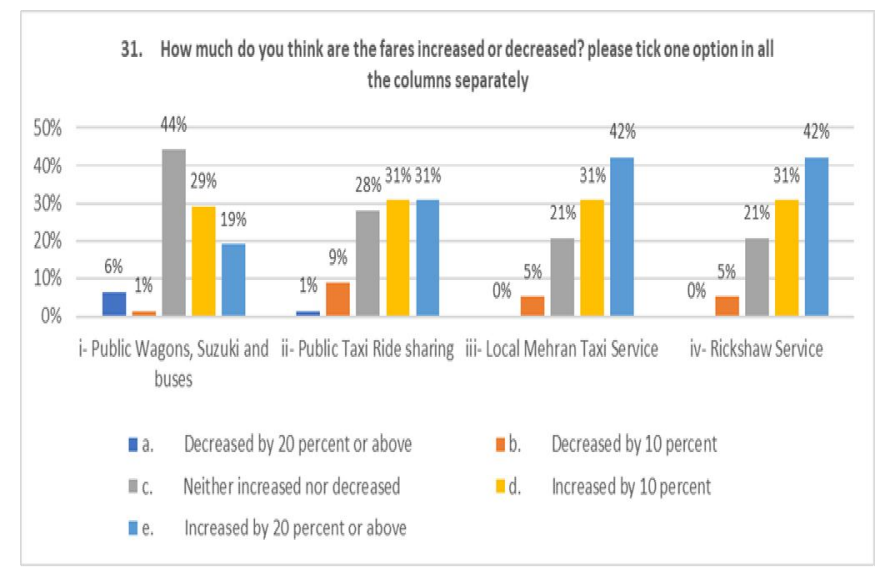

Figure 6: Graph showing the increase/decrease in fares

We can see that the fares have increased for all modes of transport from the above graph.

\subsubsection{Rents Increase/ Decrease}

According to the different studies we found our that areas where BRT passes nearby any Commercial or residential area, it is seen that the rents and property values increase in those areas. So, we wanted to find the same for Peshawar as well and got the results below.

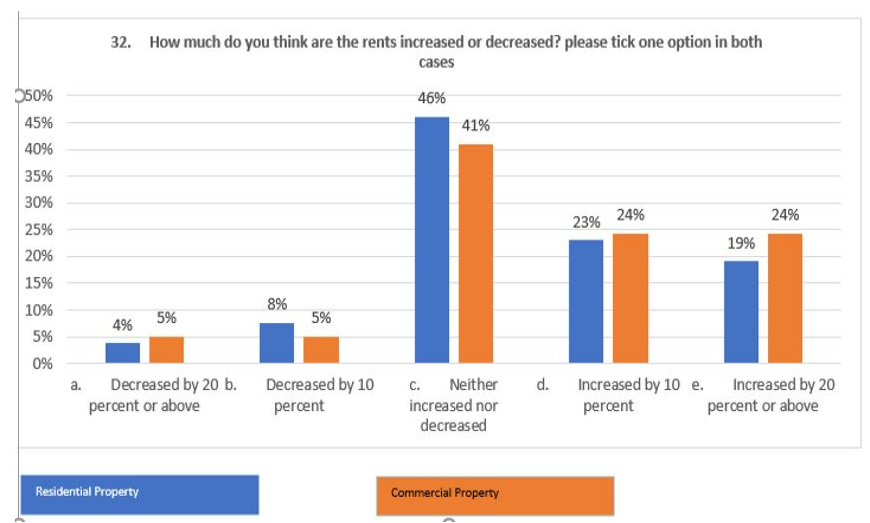

Figure 7: Graph showing the increase/ decrease in rents

From the above graph we got the results that in residential areas, 46 percent responded in the favor that rents have neither decreased nor increased. While 42 percent responded that rents have increased. On the other hand, commercial properties rents have increased according to 48 percent of the respondents while 41 percent of the respondents responded that the rents have neither decreased nor increased.

\subsubsection{Impacts on Businesses}

It was observed that almost all businesses suffered losses. The response was divided into two, because I wanted to get responses of those who are owning a business near the BRT corridor.

The first question was whether you own a business along the BRT route, and second one was the economic loss or gain in business. The results are as under.

34. Are you having a business along the BRT route? please tick one option

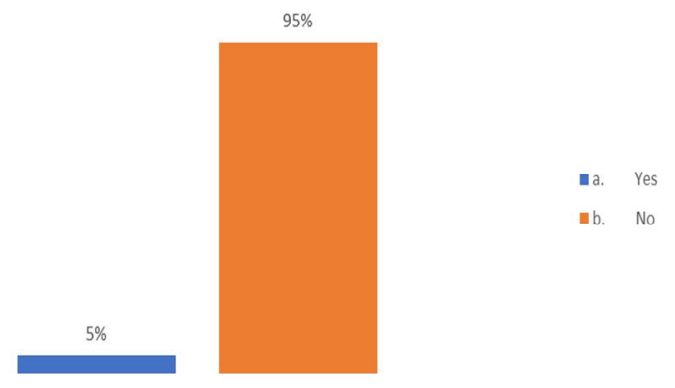

Figure 8: Graph showing the portion of population operating businesses along BRT route

The next question was asked from this 5 percent of the population who responded in Yes to the above question. And it was according to the increase/ decrease in sales. 
35. how much do you think are your sales increased or decreased? please tick one option
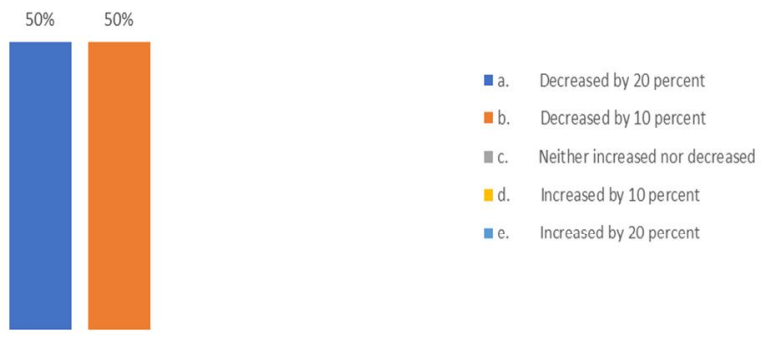

Figure 8: Graph showing increase/ decrease in sales

We observed that those who were operating businesses on BRT route during the construction time, their businesses were badly impacted. And the sales have actually been decreased by 10 to 20 percent for all 5 percent of the respondents mentioned above.

\section{CONCLUSIONS}

In this research we identified difference factors that needed to be studied before the BRT construction activity was started. It was found that the BRT construction activities have badly impacted the inhabitants of Peshawar in every possible way. Below are some of the conclusions that we drew from the above research

- It was found from the data that the changes in commute timing during the construction was caused because of Traffic congestion and narrowing of roads due to BRT Construction activities.

- The meeting frequency was reduced for those who were meeting their friends and family very frequently and those who were meeting their friends and family very rare their meeting frequency either got increased or had no change.

- Pedestrian Road crossings had become difficult during the construction time as 87 percent of respondents were in the favor of the statement that Pedestrian crossings have become difficult for them and the major reason for difficulty in road crossing was due to the distance between the flyovers or underpasses.

- Vehicular U-turns had become difficult during the BRT construction activity.

- Overall, the fares increased during the construction activity of BRT for all means of transport while a very minor percentage of respondents were in the favor that the fares have actually decreased.

- For half of the respondents the rents had neither increased nor decreased in both commercial and residential areas while for 42 percent of respondents were in the favor that rents have increased in residential areas also 48 percent think that the rents of commercial properties have increased.

- The small businesses who were operating during the construction activity of BRT were badly impacted and all the respondents responded that their sales have decreased.

\section{FUTURE SCOPE}

- This research can be used as a key stone from post occupancy evaluation of BRT Peshawar.

- The impacts of huge construction can be minimized by studying the pre-evaluation of the project and doing live surveys. This research can help identify problems for such future projects in other cities.

- The during construction impacts should be studied while preparing the feasibility report of any project.

\section{ACKNOWLEDGMENTS}

I would like to express my special thanks of gratitude to my supervisor, Dr. Salman Saeed who gave me a golden opportunity to work on this project on the topic; which also helped me in doing a lot of research and I came to know about so many new things. I am really thankful to him.

Secondly, I would like to thank my parents, my siblings and my fiancé who supported me morally which instead helped me in finalizing this project with in the limited time frame.

\section{REFERENCES}

[1] T. Peshawar, "Trans Peshawar," 2017, 2017. http://transpeshawar.pk/ (accessed Mar. 11, 2018).

[2] Pakistan bureau of statistics, "No Title," 2018, 2018. http://www.pbs.gov.pk/ (accessed Feb. 28, 2018).

[3] Transpeshawar, "Khattak breaks ground for peshawar BRT," 2017. http://transpeshawar.pk/news/khattak-breaks-ground -for-peshawar-brt/ (accessed May 23, 2018).

[4] R. Hussain, M. Hussain, M. Hussain, R. Chand, and S. Asgha, "Implementation of BRT System in Peshawar City (Pakistan): A Methodology for Case Study Analysis," J. Mech. Contin. Math. Sci., vol. 15, no. 2, pp. 137-148, 2020.

[5] S. F. Ahmad and S. I. Ahmad, "Should we Build Mega Transport Project in Cities? The Case of TransPeshawar Pakistan," Int. J. Exp. Learn. Case Stud., vol. 4, no. 1, pp. 63-73, 2019.

[6] M. tahir Masood, A. Khan, and H. A.Naqvi, "transportation problems in developing countries Pakistan: A Case-in-point," Int. J. Bus. Manag., vol. 6, 2011.

[7] D. Mahadevia, R. Joshi, and A. Datey, Low-Carbon Mobility in India and the Challenges of Social Inclusion: Bus Rapid Transit (BRT) Case Studies in India. 2013.

[8] K. Small, D. Edwards, and L. Sheridan, "A Flexible Framework for Evaluating the Socio-Cultural Impacts of a (Small) Festival," Int. J. EVENT Manag. Res., vol. I, 2005.

[9] ADB, "Project Administration Manual," 2017. 